ASE-15-0162

Research Report

\title{
How the distinctive cultures of osteopathic and allopathic medical schools affect the careers, perceptions, and institutional efforts of their anatomy faculties: A qualitative case study of two schools
}

\author{
James J. Brokaw ${ }^{1}$, Jessica N. Byram¹, Courtney J. Traser ${ }^{1}$, Tafline C. Arbor ${ }^{2}$ \\ ${ }^{1}$ Department of Anatomy and Cell Biology, Indiana University School of Medicine, Indianapolis, \\ Indiana \\ ${ }^{2}$ Division of Biomedical Sciences, Marian University College of Osteopathic Medicine, \\ Indianapolis, Indiana
}

Running title: Anatomy faculty perceptions at two schools

Correspondence to: Dr. James J. Brokaw, Department of Anatomy and Cell Biology, Indiana University School of Medicine, 635 Barnhill Drive, MS-5035, Indianapolis, IN 46202, USA. E-mail: jbrokaw@iupui.edu

This is the author's manuscript of the article published in final edited form as:

Brokaw, J. J., Byram, J. N., Traser, C. J., \& Arbor, T. C. (2015). How the distinctive cultures of osteopathic and allopathic medical schools affect the careers, perceptions, and institutional efforts of their anatomy faculties: A qualitative case study of two schools. Anatomical Sciences Education, [Preprint]. http://doi.org/10.1002/ase.1582 


\begin{abstract}
Anatomy faculties are integral to basic science instruction in medical schools, particularly given the preponderance of anatomic instruction in the preclinical curriculum. Recent years have witnessed major curricular restructuring and other emerging national trends that pose significant challenges to anatomists. An examination of anatomy faculty perceptions at two philosophically distinct medical schools within this shifting climate provides an indicator of how different institutional characteristics may impact anatomy instruction and other faculty responsibilities. Semi-structured interviews of anatomy faculty from a large, well-established allopathic medical school (Indiana University School of Medicine) and a small, new osteopathic medical school (Marian University College of Osteopathic Medicine) were explored using qualitative thematic analysis. Four overarching themes were identified: (1) Institutional philosophies, such as affiliation with osteopathic versus allopathic medicine, have minimal impact on how the anatomical sciences are taught; (2) Differences in anatomy faculty experiences at these two institutions are largely driven by the institution's size and history. There is disparity between institutions in the relative importance of teaching and research, but an ability to do research is important for both faculties; (3) Anatomy instruction and research agendas are driven by personal philosophies and interests rather than institutional philosophy; (4) Autonomy is highly valued by anatomists at both institutions. All of the participants share a devotion to educating future physicians. In fact, this study identified more similarities than differences in these two faculties. Finally, we argue that shared educational resources and research collaborations can improve anatomy education and faculty development at both institutions.
\end{abstract}


Key Words: Anatomy faculty, gross anatomy education, medical education, osteopathic medicine, allopathic medicine, institutional culture, faculty development 


\section{INTRODUCTION}

Faculty members in the basic sciences face numerous challenges to develop and sustain successful academic careers. This has always been the case, but the growing financial strain on our nation's medical schools and academic health centers is making it increasingly difficult for faculty members to fully satisfy the institutional expectations of teaching, research, and service (DaRosa et al., 2011; Dzau et al., 2013; Stimpson et al., 2014). Funding from the National Institutes of Health has fallen dramatically in recent years (Alberts et al., 2014), and publicallysupported medical schools have seen their state funding steadily dwindle as a percentage of the school's operating budget (AAMC, 2015). In this era of diminished resources, basic science faculty must work harder and juggle more responsibilities than ever before, potentially leading to what Holleman and Gritz call “biomedical burnout” (Holleman and Gritz, 2013). This environment is especially daunting for junior faculty, who must successfully navigate the vagaries of the promotion and tenure process.

As a subset of basic scientists, anatomists face additional challenges related to the teaching mission. Anatomists tend to have heavier teaching loads than most basic science faculty, owing to the dominance of anatomy content in the preclinical curriculum, which traditionally includes gross anatomy, embryology, histology, and neuroanatomy (Drake et al., 2009; Drake et al., 2014). This heavy teaching responsibility, coupled with the ever-growing list of service commitments, can genuinely erode the time available to pursue the research and scholarly work needed for promotion and tenure (Seifert et al., 2015). Moreover, new educational paradigms are transforming the teaching of anatomy at medical schools across the country, altering the traditional notions of discipline-specific instruction (Finnerty et al., 2010; Irby et al., 2010; Bolender et al., 2013). Although the current curricular reform movement and the rise of "integrated" curricula may prove beneficial to the education of physicians over time, these 
reforms are also likely to have unanticipated consequences—some positive, some not—on anatomy faculty members' job satisfaction and sense of autonomy (Chung et al., 2010; Bunton et al., 2012; Hopkins et al., 2015). The academic landscape is very different from past decades, and anatomists must be resilient and adaptable to succeed.

Any consideration of anatomy faculty at medical schools should rightfully include the perspectives of faculty at osteopathic schools. There are 31 accredited colleges of osteopathic medicine in the United States and that number is growing (AACOM, 2015). According to current projections, $25 \%$ of all medical school graduates will be doctors of osteopathic medicine (D.O.s) by 2019 (Gevitz, 2009). Anatomy has always had a strong presence in the osteopathic curriculum due to the philosophical underpinnings of osteopathic medicine and its emphasis on the musculoskeletal system (Paulus, 2013; Tyreman, 2013). The founder of osteopathy, Andrew Taylor Still (1828-1917), espoused the unorthodox theory that human disease was caused by misaligned bones, particularly of the spinal column, which Still believed disrupted nervous outflow and impaired the circulation of blood and other bodily fluids (Gevitz, 2009). By manually manipulating the bones to remove all obstructions and impingements, Still reasoned that the appropriate structure-function balance could be restored, thereby facilitating the free flow of blood and the body's natural healing processes (Paulus, 2013; Tyreman, 2013). Although Osteopathic Manipulative Therapy (OMT) no longer holds the dominate place in osteopathic practice that it once held (Johnson and Kurtz, 2001), it nevertheless remains a mainstay of osteopathic medical school training (Shannon and Teitelbaum, 2009). It is unclear how much influence, if any, the heritage of OMT has on the teaching of anatomy in the preclinical osteopathic curriculum. 
The anatomy faculty at osteopathic institutions face many of the same challenges as their colleagues at allopathic medical schools, as well as a unique set of challenges arising from osteopathic medicine's particular evolution as a distinct health profession in this country. Historically, schools of osteopathic medicine have not embraced the research orientation that is prevalent among allopathic schools (Gevitz, 2001; McGrath, 2013). Rather, the emphasis is on the teaching mission. Consequently, the anatomy faculty at osteopathic medical schools typically have fewer resources to conduct research and less time to do so when compared to their allopathic counterparts (Gevitz, 2001; McGrath, 2013).

Since its founding in 1903, the Indiana University School of Medicine (IUSM) had been the only medical school in the state of Indiana. This changed in 2013 when the Marian University College of Osteopathic Medicine (MU-COM) matriculated its first entering class in Indianapolis. The arrival of MU-COM offered a unique opportunity for collaboration between medical schools, and the anatomy faculty at both institutions were quick to establish a mutuallybeneficial partnership involving teaching and research. The anatomy faculty of IUSM and MUCOM share many similarities in background and work life, but there are also notable differences in career trajectories and work experiences imposed by the values and traditions of their respective institutions, as well as the allopathic-osteopathic distinction.

Anatomy faculty at IUSM and MU-COM were interviewed about their academic careers at an allopathic or osteopathic medical school. These interviews were analyzed using a thematic analysis with the aim of addressing the following research questions: (1) Does the philosophical orientation of the medical school (i.e., allopathic or osteopathic) influence how anatomists teach or conduct research?; (2) How are the career goals, challenges, and satisfactions of anatomists working for an osteopathic school different from those working for an allopathic school? 
This qualitative case study provides a candid snap-shot of anatomy faculty life at two philosophically distinct medical schools in the Midwestern region of the U.S. To the best of our knowledge, this is the first attempt to employ qualitative inquiry to characterize the experiences and attitudes of anatomists at allopathic versus osteopathic medical schools.

It is of interest that the allopathic and osteopathic medical professions have recently adopted a single accreditation system for postgraduate training, which will allow graduates of allopathic and osteopathic medical schools to complete their residency and/or fellowship education in programs accredited by the Accreditation Council for Graduate Medical Education and demonstrate achievement in a common set of competencies for the practice of medicine (ACGME, 2015). Viewed in this context, the partnership between IUSM and MU-COM may represent a similar opportunity for mutual cooperation and alignment between historically distinct branches of the medical profession.

\section{MATERIALS AND METHODS}

\section{Study Setting}

Indiana University School of Medicine

Indiana University School of Medicine (IUSM) is the second largest medical school in the country, with over 2,000 full-time faculty members and more than 1,400 medical students distributed among nine IUSM campuses. This statewide system of medical education has its origins in the late 1960s, when IUSM responded to the state's growing demand for physicians by establishing regional branch campuses outside the Indianapolis metropolitan area. Approximately $40 \%$ of the matriculating students are assigned to the main campus at Indianapolis, where they complete all four years of medical school. The other $60 \%$ are dispersed 
across eight regional campuses associated with local universities at Bloomington, Evansville, Fort Wayne, Gary, Muncie, South Bend, Terre Haute, and West Lafayette. After finishing their preclinical training, these students can either remain at the regional campus to complete their third and fourth years, or they can transfer to Indianapolis for their final two years. The initial assignment of students to a regional campus or Indianapolis is based on a combination of student preference, availability of space, and the school's diversity needs (e.g., equitable gender distribution). The class size at the regional campuses ranges from 24 to 36 first-year students. At the Indianapolis campus, the site of this study, the first-year class size is about 160 students.

As a state-supported medical school, IUSM gives preference to Indiana applicants, who typically comprise $75-85 \%$ of the entering class. In the last three years, the demographic composition of the entering class has been $44 \%$ female and $17 \%$ under-represented minority, with an average age of 23.

At the present time, IUSM has a traditional $2+2$ curricular model with the first two years focused on the basic sciences and the last two years devoted to clinical rotations. The basic science courses are discipline-based with relatively minimal integration of clinical content. The anatomical sciences are taught in three separate courses: gross anatomy, histology, and neuroscience. Embryology content is incorporated primarily within the gross anatomy or histology courses. Gross anatomy offers a full cadaveric dissection at all campuses, and histology is taught using both optical and virtual microscopes, with some faculty preferring one method over the other depending on the campus. Details about the gross anatomy course taught at the Indianapolis campus are shown in Table 1. The neuroscience course includes elements of neurophysiology, neuropharmacology, and neurology, in addition to classical neuroanatomy. The pedagogies used to teach these courses include Problem-Based Learning, Team-Based Learning, 
and traditional lectures. Each campus tends to emphasize a particular pedagogy, but at the Indianapolis campus lectures are the predominate mode of instruction. Beginning with the 20162017 academic year, IUSM will implement a new curriculum with greater longitudinal and horizontal integration of content, eliminating the stand-alone anatomy courses and combining subject matter across disciplines in organ system-based modules.

All anatomy instruction falls under the auspices of the Department of Anatomy and Cell Biology, headquartered at the Indianapolis campus. Each regional campus has its own complement of anatomists with faculty appointments in the department. There are 27 full-time anatomy faculty members at the Indianapolis campus, 17 of whom have at least some involvement teaching medical students. Most of the Indianapolis faculty members are researchfocused with funded laboratories. Relatively few faculty members are teaching-focused with heavy course loads. All of the teaching faculty have Ph.D. degrees in the biomedical sciences and all have full-time academic appointments.

\section{Marian University College of Osteopathic Medicine}

Marian University College of Osteopathic Medicine (MU-COM) is Indiana's newest medical school and the only school in the state to train osteopathic physicians. The development of MUCOM was largely the result of a partnership between the Indiana Osteopathic Association and Marian University to build a medical school focused on increasing the number of primary care physicians for underserved populations in both rural and urban Indiana. In addition, Marian University's mission to create transformational leaders and its expanding emphasis on healthcare education made the development of a private medical school a desirable part of its growth. MUCOM was awarded provisional accreditation on July 1, 2012, by the American Osteopathic 
Association's Commission on Osteopathic College Accreditation (COCA) and matriculated its first class of medical students in August of 2013. Full accreditation is expected in 2017 with the graduation of its inaugural class. Each first-year class matriculates 162 students for a current total of 473 medical students distributed across the first three years of the undergraduate medical curriculum (presumably over 600 students when a fourth year class begins in 2016). Preclinical instruction is delivered in the Michael A. Evans Center for Health Sciences Education on the campus of Marian University in Indianapolis. With MU-COM's inaugural class presently in their third-year rotations, clinical instruction is almost exclusively in Indiana (> 99\%) and distributed among sites from more than 40 affiliated hospitals and networks. MU-COM currently employs 30 full-time faculty members, including 17 basic science and 13 clinical faculty members.

In its first three years, the demographics of MU-COM's incoming class have been $48 \%$ female and 7\% under-represented minority. The average age of incoming students was 25 years. Indiana applicants are given preference as part of MU-COM's focus on reducing the shortage of primary care physicians in Indiana. However, local competition with a more affordable and wellestablished medical school (i.e., IUSM) and the need to maintain competitive entrance standards contribute to an average of $54 \%$ of incoming students having Indiana residency.

The MU-COM curricular model devotes much of the first two preclinical years to clinicallyintegrated basic science content and the last two years to clinical rotations. The preclinical curriculum is competency-based, integrated, and includes early clinical training. The basic science curriculum opens with two large foundational courses running concurrently: Essential Clinical Anatomy and Development, and Scientific Foundations of Medicine. The former is a clinically-oriented gross anatomy and development course with full cadaveric dissection (Table 1); the latter is a multidisciplinary basic science course integrating an introduction to histology. 
All other basic science courses are systems-based and integrate both basic science disciplines and clinical content. Gross anatomy, embryology, and histology are taught in essentially every one of the systems courses, but neuroanatomy is primarily taught in a neuroscience course, soon to be a combined neuroscience/eye, ear, nose, throat/musculoskeletal systems course. The pedagogical design of the curriculum largely involves lectures, but also includes case-based, team-based, and problem-based learning. The School uses virtual histology rather than traditional microscopy.

The delivery of the anatomy component within the preclinical curriculum is by a small group of anatomy faculty within the Division of Biomedical Sciences. The university employs 4 fulltime anatomy faculty members, all of whom participate extensively in both lecture and laboratory instruction. All of the anatomists have Ph.D. degrees in the biomedical sciences and all have full-time academic appointments. Scholarship is a required component of MU-COM's anatomy faculty efforts; nevertheless, none of MU-COM's anatomy faculty members have primary research appointments. Indeed, institutional research support for the anatomists is negligible in terms of facilities, capital equipment, and start-up or other funding, although the university is currently planning to build a small, shared research space for the anatomy faculty. Teaching and service commitments compose relatively high percentages of anatomy faculty workloads, although the lead anatomist, a department chair equivalent, additionally carries a heavy administrative workload.

\section{Participants}

The participants included five faculty members from the Department of Anatomy and Cell Biology at the Indianapolis campus of IUSM, and four faculty members from the Division of 
Biomedical Sciences at MU-COM (Table 2). The faculty participants were solicited using a standardized email sent from the research team in June 2015 that detailed the aims and purposes of the study. The five faculty participants from IUSM were purposefully recruited from a larger pool of anatomy faculty $(n=27)$ to achieve a representative sample of both teaching-focused and research-focused faculty with junior and senior rank. MU-COM employs four anatomy faculty members, all of whom agreed to participate in the study and included teaching-focused faculty with junior rank. The authors recognize that most faculty engage in both teaching and research to varying degrees, but for the purpose of this study, faculty participants were defined as being either teaching-focused or research-focused based on their predominate roles in the institution and the focus of their faculty efforts. All nine of the participants taught histology, embryology, and/or gross anatomy to medical students. One of the MU-COM participants also taught neuroanatomy. The Institutional Review Committee of IUSM granted exempt status to this research.

\section{Data Collection}

To determine faculty perceptions regarding the manner in which institutional philosophies impacted their teaching of anatomy and their responsibilities as faculty members, semi-structured interviews were conducted with each participant. Following written consent to participate in the study, anonymous identification numbers were assigned to each participant in order to preserve the participants’ privacy and decrease any potential researcher bias during the analysis phase. Participants were informed that the location of the interview would be conducted in a place of their choosing, and most preferred to conduct the interview in their office or at an on-campus site. Participants were then emailed a copy of the semi-structured interview protocol so that they 
would have an opportunity to review the interview questions in advance. The semi-structured interviews were used as a prompt to engage the participants, but the interviews were not limited to the questions stated in the interview protocol and not all questions from the protocol were asked in each interview. The interview questions were designed to stimulate discussion, but additional questions were prompted from the participants’ responses during the interviews. Examples of the interview questions are listed in Table 3. Each interview was conducted by two members of the research team (J.N.B. and C.J.T.) and each interview lasted approximately 45 minutes.

All interviews were audio-recorded using AudioNote, version 3.5.2 (Luminant Software, Inc., Austin, TX). Audio files were labeled with their respective identification numbers and uploaded to a password-protected site on the IUSM server immediately following the completion of each interview.

\section{Data Analysis}

To conduct the thematic analysis, audio files were transcribed verbatim into written form by one researcher (J.N.B.) and double-checked for accuracy by another researcher (C.J.T.). The interview transcripts were evaluated using a thematic analysis for a descriptive case study (Merriam, 1985). Transcripts were repeatedly and actively read with the intent of generating a patterned coding scheme from which broader themes could be elucidated. Each transcript was then coded in duplicate (J.N.B. and C.J.T.) by institution (Braun and Clarke, 2006). In instances where the researchers noted coding discrepancies, codes were reanalyzed until a consensus was reached (Guest et al., 2012). Codes from both institutions were then sorted and aggregated into 
overarching themes, which were exhaustively reviewed in order to ensure an accurate representation of the data (Braun and Clarke, 2006).

\section{RESULTS}

The semi-structured interviews explored several broad topics related to the academic careers of the anatomists at IUSM and MU-COM. Four overarching themes emerged from the analysis, which are detailed below.

\section{Theme 1. Osteopathic versus allopathic medicine: A distinction without a difference for} anatomists.

When participants were asked to share their interpretations of osteopathic versus allopathic medicine, many noted a merging of the two medical professions and believed that the similarities far outweighed the differences. However, several IUSM and MU-COM participants mentioned the key osteopathic principle of holism, or treating the whole patient rather than addressing only a patient's symptoms, which these participants contrasted with their perception of the allopathic approach — an emphasis on the etiology and mechanism of disease and its treatment with pharmacological agents. As stated by one IUSM participant, "I think the approach of an allopathic physician in the way we train them is to treat the symptom, whereas in an osteopathic setting it's more about treating the patient as a person...its more about holistic education.” This was not a consensus opinion, however, as participants from both IUSM and MU-COM believed that allopathic schools also promoted the holistic viewpoint. Nevertheless, there was general agreement among the participants that there were few substantive differences between osteopathic and allopathic physicians in terms of scope of practice, other than large-scale trends 
in specialty choice. For example, the common perception was that doctors of osteopathy (D.O.s) were more likely to practice primary care in rural communities, whereas medical doctors (M.D.s) were more likely to enter specialty fields. But in terms of their medical school training, the participants felt that D.O.s and M.D.s had essentially equivalent educations, as both are expected to master much of the same body of knowledge.

Regardless of any theoretical differences between osteopathic and allopathic medicine, most of the participants from both faculties were emphatic that their teaching of anatomy would remain constant regardless of the type of medical institution they were affiliated with, and that the institutional principles had no influence on their teaching of anatomy. Anatomy was simply anatomy, taught with no discernable slant to the osteopathic or allopathic principles. All of the participants believed that the anatomy curricula at their respective institutions were teaching essentially the same content, with only minor differences in pedagogy or curricular structure (e.g., organ systems-based versus discipline-based). In fact, several faculty members from both IUSM and MU-COM concluded that the only distinction between osteopathic and allopathic medical schools was that osteopathic schools include Osteopathic Manipulative Medicine/Therapy (OMM or OMT) in their curricula. While the MU-COM faculty felt that some of the concepts taught in the OMM courses reinforced anatomical concepts, the presence of OMM courses in the curriculum had no influence on how they taught anatomy in the basic science years. In response to the question of how one personally relates to the osteopathic philosophy, one MU-COM faculty member stated, "here [anatomy] is really shored up by OMT because it is anatomic. It is very much reinforcing the importance of anatomy. Me personally, in terms of osteopathic flavors, I am a scientist. I am not a clinician. So [osteopathic philosophy] 
doesn't make much of a difference to me." This attitude exemplified the MU-COM participants as a whole.

Some of the faculty at IUSM believed that the inclusion of OMM in the osteopathic curriculum meant there was a particular emphasis on teaching the musculoskeletal anatomy of the back, because that region is often the focus of OMM therapy. However, as noted by a MUCOM faculty member, "Nothing could be further from the truth. We are holistic and everything is important... My teaching style is not restricted in any way to serve [the OMM] focus." This sentiment was echoed by other MU-COM faculty members who believe that anatomy is reinforced in the OMM courses but OMM does not influence the teaching of anatomy: "Osteopathic principles do not influence our teaching of anatomy... I'd give the same lectures at an allopathic school if I shifted," stated one participant. The majority of participants from both faculties acknowledged that teaching in the anatomical sciences is very time consuming; however, most maintained great satisfaction in teaching medical students and believed that it benefited their careers.

\section{Theme 2. Institutional differences: Foundational not philosophical.}

The participants were asked to express some of the challenges and successes they have experienced as faculty members at their respective institutions. Reiterating the major theme that the philosophy of the medical institution had no influence over their teaching, the participants also expressed the general view that their individual experiences as faculty members were shaped more by the institution's size and history, rather than any overarching osteopathic versus allopathic philosophy. MU-COM is a fledgling medical school associated with a small, private, liberal arts university, whereas IUSM is a long-established medical school associated with a 
large, state-supported, research university. The participants recognized that these different academic environments provided different opportunities and expectations for the faculty.

The relative importance of teaching versus research for career advancement was a recurring topic during the interviews. Several of the participants from both IUSM and MU-COM believed that the primary mission of allopathic institutions was to conduct cutting-edge biomedical research; thus, the majority of allopathic faculty members were research-focused and promotion and tenure (P\&T) was generally based on their triumphs as researchers. Conversely, teaching was felt to be the principal focus of osteopathic institutions. Because osteopathic faculty members tend to be more teaching-focused than research-focused, the MU-COM faculty indicated that their teaching evaluations and evidence of teaching effectiveness were especially important for P\&T. The research-focused faculty at IUSM emphasized the increasing difficulty of obtaining grant support to fund their laboratories and research agendas, while the teachingfocused faculty at both schools appreciated that they were not expected to compete for federal grants with the same stringency as their research-focused colleagues.

Nevertheless, the ability to conduct research was an important consideration for all the faculty participants. Many expressed both challenges and successes with regard to institutional support of research, as reflected in the provision of space and equipment and the availability of dedicated time to conduct research. Most of the MU-COM faculty hailed the quality of their new teaching facilities, but lamented the lack of research space afforded to them and other basic science faculty. Essential laboratory equipment was lacking and the existing research infrastructure was inadequate. As such, the MU-COM faculty expressed serious reservations about their ability to meet the research expectations for P\&T. Conversely, IUSM faculty spoke favorably of the institutional support for research in terms of start-up packages and laboratory 
space, but were very concerned about the School's new policy requiring the faculty to cover a greater portion of their salaries through grant support.

One factor that was viewed particularly favorably by the IUSM anatomy faculty was support throughout the P\&T process. Many stated that the expectations for P\&T were clearly defined at both the university and departmental levels. One senior faculty member noted, "Promotion is doable. Tenure is doable. There is a tremendous effort put forth by the School of Medicine to provide guidance in the process." Additionally, some participants celebrated the ability to act as mentors to junior faculty during the P\&T review process. Likewise, junior faculty members were grateful for the mentoring and other guidance provided by the department and university. By contrast, MU-COM faculty expressed reservations about the P\&T expectations for research and scholarship that have been set forth by their university. From their perspective, the expectations are vague and perhaps not realistic given the modest institutional support for research. While the MU-COM faculty did appreciate not having to obtain grant funding to support their salaries, they also lamented the lack of money, resources, and laboratory space dedicated for research purposes. Several faculty members who arrived at MU-COM with established research programs had to modify their interests to conform to the limited research support made available to them (e.g., transition from a morphological research focus to medical education topics). As stated by one participant, "we are a little beside ourselves as a faculty, particularly the anatomy faculty, about how we are going to meet the benchmark that has been set for us and not having the resources available to us." Other MU-COM faculty members whose research interests require only modest support had fewer criticisms regarding the institutional backing for research. 


\section{Theme 3. Personal philosophy transcends institutional philosophy.}

None of the participants from either faculty felt that their institution's philosophy of medicine had any influence in the way they conducted their work. Rather, each faculty member cited a personal philosophy or approach that drove his or her teaching and research interests. One MUCOM faculty member explained that, "the study of anatomy is approached as its own discipline and [we] try to do [this] as completely and thoroughly as possible.” As expressed by one IUSM participant: "I have never been encouraged in any way to consider allopathic principles or any other aspect of medicine as important to what I do. And indeed my approach has always been just to do the best job possible in presenting information about the anatomy the best I can. Not from a perspective but just to give really, really strong information: defensible, evidence-based information."

All of the participants noted that their teaching styles were heavily influenced by their personal undergraduate and/or graduate training and their own interpretation of the curriculum, rather than any theoretical underpinnings of the institution. For example, one IUSM participant who trained as a biomedical researcher noted that his teaching style was reflective of his interpretation of anatomy rather than the philosophical tenets of the institution: "It doesn't really matter what concept or principle of medicine is behind my institution. It's that I have a perspective on the anatomy and want to try to present as thorough a discourse as possible to my learners." Other participants emphasized that their pedagogical methods were based on the desire to produce knowledgeable physicians, regardless of the theoretical basis: "I am training physicians. I am not training OMM specialists. I am not training [specialists]. I am training physicians.”

In a similar manner, the participating faculty indicated that their research agendas were not influenced by the philosophy of their institution. Regardless of the osteopathic or allopathic 
distinction, all of the anatomists included in this study had an interest (at one time or another) in a particular research niche, which they pursued to the best of their abilities with the resources available. However, some faculty noted that their interest in working at a specific institution was based on the need to identify a setting or "environment that not only encouraged but supported research.” One IUSM faculty member stated that his employment at IUSM was solely based on the research opportunities afforded to him: “My decision [to not accept employment at a D.O. school] had nothing to do with it being an osteopathic school and everything to do with the setting for research.”

\section{Theme 4. Anatomists value autonomy.}

As the participants shared their satisfactions and challenges of being a faculty member at their respective institutions, many mentioned their sense of autonomy as being an important factor in their overall job satisfaction. The MU-COM faculty expressed appreciation at being part of a cohort of foundational faculty that played a significant role in building the curriculum for a new medical school. In explaining what factors influenced the acceptance of a faculty position, one participate stated: “It wasn't because it was a D.O. school. I'll say that plainly. It was because it's a new school. It was the ability to be in at the ground floor and to create a curriculum and have the power to teach the way we wanted to teach and what we wanted to teach." The MU-COM faculty valued the autonomy they were given to construct the entire anatomy curriculum to their own standards and to modify it as they deemed necessary. By contrast, several of the IUSM participants admitted that their own sense of autonomy was beginning to dissipate. As a result of curricular revisions at IUSM, the anatomy faculty will no longer be able to teach with the same freedoms they once enjoyed. There was a general perception of too much 
"top-down” control of the curricular reform process, contributing to a general decline in job satisfaction. As one faculty member stated, "Until Fall of 2016, [the administration] has never really told us what we had to teach."

However, the autonomy enjoyed by the small MU-COM faculty was noted to come at the price of burdensome teaching loads and service duties, further reducing the amount of time available for research and scholarly activity. Conversely, the larger size of the IUSM faculty enabled the teaching load to be more evenly distributed across the faculty. Reflecting on experiences teaching in the gross anatomy lab, one IUSM participant stated: "You have a small group of really dedicated education faculty, teaching faculty, and you are able to sprinkle in basic science researchers who have a strong teaching background to come in and fill the gaps and also bring a basic science perspective into the lab."

Having dedicated teaching and research faculty was viewed as a particular benefit at IUSM, which allowed the faculty to focus their efforts on either teaching or research without having to sacrifice the other.

\section{DISCUSSION}

Through the methodology of semi-structured interviews and thematic analysis, this case study has explored the experiences and attitudes of anatomy faculty members at two medical schools representing distinct branches of the medical profession, allopathic and osteopathic medicine. The four themes that emerged from our analysis revealed striking similarities as well as notable differences between the two faculties. We discuss these findings and their implications for faculty development within the context of our original research questions. 


\section{Does the philosophical orientation of the medical school (i.e., allopathic or osteopathic) influence how anatomists teach or conduct research?}

The answer appears to be a resounding no. With regard to teaching, the faculty at IUSM and MU-COM both share the strong conviction that anatomy is an important discipline in its own right, and its presentation should not be influenced to conform to a particular philosophy of disease causation or treatment. This is not to say that anatomy is not taught without regard to clinical relevance, as both faculties take great pains to incorporate clinical topics throughout their courses to instill in students an appreciation of why mastery of the subject matter is important to clinical practice. However, there is no deliberate effort to present material thought to be especially relevant to allopathic or osteopathic practitioners. This finding dispelled the misconception of even the IUSM anatomists, who were of the belief that their MU-COM colleagues taught gross anatomy with an emphasis on musculoskeletal anatomy and OMM; both faculties teach comprehensive anatomy courses with full cadaveric dissection. Throughout the interviews, all of the faculty participants conveyed a sense of pride in what they do. They identify first and foremost as anatomists and scientists, not in any way subservient to the theoretical underpinning of their institutions. They take their teaching responsibilities seriously and believe they have important roles in educating students to be competent medical practitioners, regardless of the M.D. or D.O. label.

Likewise, the particular lines of research pursued by the faculty at IUSM and MU-COM are not influenced by the allopathic or osteopathic orientation of the institution, per se. Each faculty member is encouraged to follow his or her own research interests, though the MU-COM faculty are seriously constrained by their institution's limited resources for research. This underscores a major distinction between allopathic and osteopathic medical schools. As noted by Gevitz, “Over 
the course of their history, osteopathic medical colleges and hospitals have not been researchoriented, and many have not even been research-friendly” (Gevitz, 2001). However, this historical artifact may be giving way to new thinking, as there have been numerous calls from within the osteopathic community for more research into the biomedical mechanisms and clinical efficacy of osteopathic manual medicine and practice (Gevitz, 2001, 2009; Shannon and Teitelbaum, 2009; McGrath, 2013), as well as increased emphasis on training osteopathic physicians in research methods (Degenhardt and Standley, 2013; Yens et al., 2014; Collins et al., 2015). There have been more recent calls for an expanded emphasis on research, including basic science and traditional clinical research, within osteopathic institutions (Clark and Blazyk, 2014), and there is anecdotal evidence that the American Osteopathic Association has increased expectations for support of institutional research to meet accreditation standards. Perhaps this will ultimately translate into expanded research opportunities for basic science faculty members at osteopathic schools, as well as the robust research infrastructure and extramural funding necessary to support the task. But in the short-term, the anatomists at MU-COM must reconcile their institution's requirements for P\&T with the limited resources available for research. Some of the MU-COM faculty members are collaborating with their IUSM counterparts on research projects of mutual interest, which will benefit both parties through the sharing of resources and expertise.

This is an application of the "community of practice" concept proposed by Strkalj and Dayal, whereby partnering medical schools co-operate and share resources to advance the objectives of both institutions (Strkalj and Dayal, 2014). The partnership between IUSM and MU-COM has proven to be especially beneficial in the educational arena, where the sharing of resources and expertise has mitigated some of the mutual challenges we face in teaching our respective 
programs (DaRosa et al., 2011). For example, IUSM and MU-COM share a common source of cadavers and utilize the same pool of laboratory teaching assistants, which provides cost-savings to both institutions and fosters cooperation rather than competition. Other examples of cooperation include the involvement of IUSM anatomy faculty members as instructors in MUCOM's neuroscience course, and the co-hosting of a faculty development workshop for the IUSM and MU-COM anatomists.

\section{How are the career goals, challenges, and satisfactions of anatomists working for an osteopathic school different from those working for an allopathic school?}

The common thread that runs throughout the interviews is a shared commitment to the teaching mission by IUSM and MU-COM faculty alike. This is perhaps not surprising given that the majority of participants are teaching-focused faculty by design, whose career aspirations are more closely aligned with teaching than research. Nevertheless, a passion for teaching is also shared by the research-focused faculty at IUSM, whose careers are defined by their research accomplishments, not their teaching roles. All of the participants convey a deep loyalty to anatomy as a discipline, replete with its own values, traditions, and fundamental principles. They care about the integrity of the anatomy curriculum and the way in which it is taught. Both faculties are similar in this regard and the career satisfactions they derive from teaching.

Most of the differences in the experiences and attitudes of the IUSM and MU-COM anatomists can be largely attributed to differences in the size and scope of the two institutions, apart from the allopathic versus osteopathic distinction, which appears to play a minor role at best. The disproportionate size of IUSM relative to MU-COM, coupled with its longer history and deeper pockets, give IUSM a very different faculty environment compared to MU-COM. 
This certainly provides advantages to the faculty in terms of resources that simply cannot be matched by MU-COM, but it also imposes strenuous expectations of research productivity. For example, like all research-driven medical schools, IUSM derives much of its operating budget from faculty-generated research grants. Therefore, the administration incentivizes the faculty to obtain federal research grants by linking a significant portion of their compensation to grant support. Moreover, the P\&T guidelines for research-focused faculty place a premium on research publications and grants, further emphasizing the preeminence of research for the institution. The relatively few teaching-focused faculty at IUSM are largely immune from these research expectations, because their compensation is tied more to tuition revenue and other teachingrelated funding sources, much like the MU-COM faculty. It remains to be seen whether IUSM's new policy regarding faculty compensation will adversely impact the teaching and service missions. For example, the growing pressures to compete for research funding in an era of declining federal grant support could have the effect of discouraging research-focused anatomists from fully participating in teaching, opting instead to concentrate on their research. There is some anecdotal evidence that this is occurring already.

The P\&T concerns expressed by the MU-COM anatomy faculty could similarly be expected to negatively impact the education and service missions of an institution in which these missions are highly valued. Pressures to successfully navigate MU-COM’s P\&T requirements for research while maintaining heavy teaching and service commitments may result in efforts by junior anatomy faculty to minimize the time devoted to teaching preparation and improvement. Teaching quality and innovation may suffer as a consequence. In a new medical school with limited support through the P\&T process and uncertain expectations, it is unknown whether the 
fears of the junior anatomy faculty are justified. But there are early indications of faculty attempts to minimize teaching and service efforts.

The anatomy faculty at IUSM and MU-COM communicated disparate stressors and rewards relating to their efforts and institutional expectations. For IUSM faculty, obtaining grant funding to support ongoing research programs and their salaries, and loss of curricular autonomy were primary stressors. For MU-COM faculty, P\&T expectations of research with insufficient institutional support and limited time for research were of concern. It should be noted, that in neither institution did the anatomy faculty consider it easy to meet institutional expectations for advancement. When selecting an anatomy faculty position at an allopathic or osteopathic medical school, applicants should carefully evaluate how well their own aspirations and desired career focus align with a given institution's culture and expectations for faculty performance. In essence, it is possible that the combination of stressors and rewards an individual would prefer over his or her career might be the most effective indicator of the better matched position, rather than characteristics of the institution itself.

Although the faculty from both schools generally expressed an upbeat attitude during the interviews, there were detectable strains of worry and discontent voiced by several of the participants. This is not unexpected given the nature of the study, except that all of the concerns seemed to be related to three specific examples of institutional governance: the salary policy and curricular reform process at IUSM, and the P\&T expectations at MU-COM. Over time, disharmony over these issues could have the potential to erode an individual faculty member's job satisfaction and what has been termed "faculty vitality" (Dankoski et al., 2012). In one recent study, researchers found that a quarter of the faculty at U.S. academic health centers lack optimal vitality, placing them at an increased risk for poor job performance and burnout (Pololi et al., 
2015). Regarding IUSM’s curricular reform process specifically, Hopkins and co-workers have made the point that the change process too often fails to adequately incorporate the views of the basic science faculty who do the actual teaching, leading to difficulties in implementation that could have been avoided (Hopkins et al., 2015). We note that the MU-COM anatomists believe they were instrumental in creating their curriculum and have a positive sense of ownership and autonomy as a result, whereas the IUSM anatomists feel alienated from the curricular reform process and have a diminished sense of autonomy. Studies have shown that attitudes about autonomy (Chung et al., 2010) and institutional governance (Bunton, et al., 2012) are both significant predictors of job satisfaction for medical school faculty.

\section{STUDY LIMITATIONS}

By their very nature, qualitative studies cannot be generalized beyond their specific study setting, but they do provide in-depth perspectives not obtainable through broad-based surveys. We suspect that the experiences and attitudes of our faculty participants may be similar to those of other anatomists teaching at allopathic and osteopathic medical schools in the United States. However, we make no claim that our results are necessarily representative of all such schools. In fact, the disparate size and scope of IUSM versus MU-COM may very well account for the findings more than the allopathic-osteopathic distinction, per se. Different findings may have been obtained if an M.D. school and a D.O. school of similar size had been compared. Another study limitation is the potential for response bias, which is inherent to interview data. To what extent our participants may have shaded their responses to give what they perceived to be “socially acceptable” answers is unknown. 


\section{CONCLUSIONS}

The results of this case study revealed rich insights into the working lives of the anatomy faculty teaching at IUSM and MU-COM. The anatomists at IUSM and MU-COM share many things in common, especially their commitment to educating the next generation of physicians. Both faculties must develop and sustain their careers within unique institutional parameters, but there are ample opportunities to collaborate in areas of mutual interest. By working together, IUSM and MU-COM can capitalize on each other's strengths to advance anatomy education at both institutions. We believe our inter-institutional collaboration may serve as a model for other allopathic-osteopathic medical school partnerships.

\section{ACKNOWLEDGEMENTS}

The authors thank the anatomy faculty members who freely gave of their time to participate in this study.

\section{NOTES ON CONTRIBUTORS}

JAMES J. BROKAW, Ph.D., M.P.H., is an associate professor and vice chair in the Department of Anatomy and Cell Biology at the Indiana University School of Medicine, Indianapolis, Indiana, where he directs the Education Track in Anatomy Ph.D. Program and teaches histology to graduate students and medical students. His research interests include curricular innovations in medical education and the development of graduate degree programs to train the next generation of anatomy teachers and educational researchers. 
JESSICA N. BYRAM, M.S., is a graduate student in the Department of Anatomy and Cell Biology at the Indiana University School of Medicine, Indianapolis, Indiana. Her research interests include medical education and professional identity formation in medical students.

COURTNEY J. TRASER, B.S., is a graduate student in the Department of Anatomy and Cell Biology at the Indiana University School of Medicine, Indianapolis, Indiana. Her research interests include medical education, instructional strategies, and physician burnout.

TAFLINE C. ARBOR, Ph.D., is an assistant professor and director of anatomy laboratories in the Division of Biomedical Sciences at the Marian University College of Osteopathic Medicine, Indianapolis, Indiana. She oversees the anatomy program at MU-COM, is course director for the medical gross anatomy course, and teaches anatomy and embryology throughout the preclinical medical curriculum. Her research interests include primate functional morphology, the evolution of human and non-human primates, and anatomy education. 


\section{LITERATURE CITED}

AACOM. 2015. American Association of Colleges of Osteopathic Medicine. U.S. colleges of osteopathic medicine. American Association of Colleges of Osteopathic Medicine, Chevy Chase, MD. URL: http://www.aacom.org/become-a-doctor/us-coms [accessed 23 July 2015].

AAMC. 2015. Association of American Medical Colleges. Revenue by source as a percentage of total revenue for medical schools with full accreditation, FY 1977 through FY 2014. Association of American Medical Colleges, Washington, DC. URL:

http://www.aamc.org/data/finance/434230/fig8-9.html [accessed 28 July 2015].

ACGME. 2015. Accreditation Council for Graduate Medical Education. Single GME accreditation system. Accreditation Council for Graduate Medical Education, Chicago, IL. URL: http://www.acgme.org/acgmeweb/tabid/445/GraduateMedicalEducation/SingleAccreditationSyst emforAOA-ApprovedPrograms.aspx [accessed 20 October 2015].

Alberts B, Kirschner MW, Tilghman S, Varmus H. 2014. Rescuing US biomedical research from its systemic flaws. Proc Natl Acad Sci 111:5773-5777.

Bolender DL, Ettarh R, Jerrett DP, Laherty RF. 2013. Curriculum integration = course disintegration: What does this mean for anatomy? Anat Sci Educ 6:205-208.

Braun V, Clarke V. 2006. Using thematic analysis in psychology. Qual Res Psychol 3:77-101. 
Bunton SA, Corrice AM, Pollart SM, Novielli KD, Williams VN, Morrison LA, Mylona E, Fox S. 2012. Predictors of workplace satisfaction for U.S. medical school faculty in an era of change and challenge. Acad Med 87:574-581.

Chung KC, Song JW, Kim HM, Wolliscroft JO, Quint EH, Lukacs NW. 2010. Predictors of job satisfaction among academic faculty members: Do instructional and clinical staff differ? Med Educ 44:985-995.

Clark BC, Blazyk J. 2014. Research in the osteopathic medical profession: Roadmap to recovery. J Am Ostopath Med Assoc 114:608-614.

Collins KA, Brannan GD, Dogbey GY. 2015. Research dissemination: Guiding the novice researcher on the publication path. J Am Ostopath Med Assoc 115:324-330.

Dankoski ME, Palmer MM, Nelson Laird TF, Ribera AK, Bogdewic SP. 2012. An expanded model of faculty vitality in academic medicine. Adv Health Sci Educ Theory Pract 17:633-649.

DaRosa DA, Skeff K, Friedland JA, Coburn M, Cox S, Pollart S, O'Connell M, Smith S. 2011. Barriers to effective teaching. Acad Med 86:453-459.

Degenhardt BF, Standley PR. 2013. 2013-2022 strategic plan for research: A role for everyone in promoting research in the osteopathic medical profession. J Am Ostopath Med Assoc 113:654659. 
Drake RL, McBride JM, Lachman N, Pawlina W. 2009. Medical education in the anatomical sciences: The winds of change continue to blow. Anat Sci Educ 2:253-259.

Drake RL, McBride JM, Pawlina W. 2014. An update on the status of anatomical sciences education in United States medical schools. Anat Sci Educ 7:321-325.

Dzau VJ, Cho A, Ellaissi W, Yoediono Z, Sangvai D, Shah B, Zaas D, Udayakumar K. 2013. Transforming academic health centers for an uncertain future. N Engl J Med 369:991-993.

Finnerty EP, Chauvin S, Bonaminio G, Andrews M, Carroll RG, Pangaro LN. 2010. Flexner revisited: The role and value of the basic sciences in medical education. Acad Med 85:349-355.

Gevitz N. 2001. Researched and demonstrated: Inquiry and infrastructure at osteopathic institutions. J Am Ostopath Med Assoc 101:174-179.

Gevitz N. 2009. The transformation of osteopathic medical education. Acad Med 84:701-706.

Guest G, MacQueen K, Namey E. 2012. Applied Thematic Analysis. $1^{\text {st }}$ Ed. Thousand Oaks, CA: Sage Publications, Inc. 320 p.

Holleman W, Gritz ER. 2013. Biomedical burnout. Nature 500:613-614. 
Hopkins R, Pratt D, Bowen JL, Regehr G. 2015. Integrating basic sciences without integrating basic scientists: Reconsidering the place of individual teachers in curriculum reform. Acad Med 90:149-153.

Irby DM, Cooke M, O'Brien BC. 2010. Calls for reform of medical education by the Carnegie Foundation for the Advancement of Teaching: 1910 and 2010. Acad Med 85:220-227.

Johnson SM, Kurtz ME. 2001. Diminished use of osteopathic manipulative treatment and its impact on the uniqueness of the osteopathic profession. Acad Med 76:821-828.

McGrath MC. 2013. From distinct to indistinct, the life-cycle of a medical heresy. Is osteopathic distinctiveness an anachronism? Int J Osteopath Med 16:54-61.

Merriam S. 1985. The case study in educational research: A review of selected literature. J Educ Thought 19:204-217.

Paulus S. 2013. The core principles of osteopathic medicine. Int J Osteopath Med 16:11-16.

Pololi LH, Evans AT, Civian JT, Gibbs BK, Coplit LD, Gillum LH, Brennan RT. 2015. Faculty vitality-Surviving the challenges facing academic health centers: A national survey of medical faculty. Acad Med 90:930-936. 
Seifert WE Jr, Cleary LJ, Strobel HW. 2015. Issues in obtaining promotion. Med Sci Educ 25:75-79.

Shannon SC, Teitelbaum HS. 2009. The status and future of osteopathic medical education in the United States. Acad Med 84:707-711.

Stimpson JP, Li T, Shiyanbola OO, Jacobson JJ. 2014. Financial sustainability of academic health centers: Identifying challenges and strategic responses. Acad Med 89:853-857.

Strkalj G, Dayal M. 2014. Working together, sharing resources: An interuniversity collaboration to advance anatomy education. Anat Sci Educ 7:501-502.

Tyreman S. 2013. Re-evaluating 'osteopathic principles'. Int J Osteopath Med 16:38-45.

Yens DP, Brannan GD, Dumsha JZ. 2014. A research primer, part 2: Guidelines for developing a research project. J Am Ostopath Med Assoc 114:41-51. 


\section{TABLES:}

Table 1: Comparison of the Gross Anatomy Courses Taught at Indiana University School of Medicine (IUSM) and Marian University College of Osteopathic Medicine (MU-COM)

\begin{tabular}{lcc}
\hline \multicolumn{1}{c}{ Course Details } & IUSM Course & MU-COM Course \\
\hline Credit Hours & 8 & 8 \\
Total Scheduled Hours & 155 & 160 \\
Lecture Hours & 55 & 60 \\
Laboratory Hours & 100 & 100 \\
Instructor/Student Ratio & $1: 14$ & $1: 28$ \\
Full Cadaveric Dissection & Yes & Yes \\
Peer Teaching & Yes & Yes \\
\hline
\end{tabular}


Table 2: Description of the Faculty Participants from Indiana University School of Medicine (IUSM) and Marian University College of Osteopathic Medicine (MU-COM)

\begin{tabular}{|c|c|c|}
\hline Career Emphasis & IUSM Faculty $(n=5)$ & MU-COM Faculty $(n=4)$ \\
\hline Teaching-Focused & $\begin{array}{l}\text { Assistant Professor } \\
\text { Senior Lecturer } \\
\text { Professor }\end{array}$ & Assistant Professor (4) \\
\hline Research-Focused & $\begin{array}{l}\text { Assistant Professor } \\
\text { Professor }\end{array}$ & \\
\hline \multicolumn{3}{|l|}{ Demographics } \\
\hline Age Range & 29 to 67 & 32 to 45 \\
\hline Years Teaching & 3 to 37 & 3 to 7 \\
\hline Sex & 5 Males, 0 Females & 2 Males, 2 Females \\
\hline Race & 4 Whites, 1 Asian & 4 Whites \\
\hline Ph.D. Field & $\begin{array}{c}3 \text { in Anatomy, } 1 \text { in } \\
\text { Functional Anatomy \& } \\
\text { Evolution, } 1 \text { in Anatomy } \\
\text { Education }\end{array}$ & $\begin{array}{c}2 \text { in Biological Anthropology, } 1 \\
\text { in Evolutionary Biology, } 1 \text { in } \\
\text { Anatomy Education }\end{array}$ \\
\hline
\end{tabular}


Table 3: Sample Interview Questions

Would you describe if and how you personally connect/relate to the guiding
principles/philosophy of your type of medical institution?
How do the principles of your institution influence how you interact with your students?
Can you give a specific example regarding how allopathic/osteopathic principles (or the
philosophy of your institution) influence your teaching of anatomy?
What do you think the single ACGME accreditation means for the future of osteopathic and
allopathic medicine?
Would you say that osteopathic medical students are fundamentally different from allopathic
medical students? How so?
How do you think that the teaching of anatomy differs in an osteopathic/allopathic medical
school?
How do you think the role of anatomy faculty differs between the two institutions?
What specific factors influenced your decision to become a faculty member at your current
medical institution?
Can you describe your requirements (i.e. type of research, scholarship, teaching requirements)
as a faculty member at your institution?
What are the expectations for promotion and tenure at your institution?
What support does the university provide you to achieve promotion/tenure expectations and
basic job requirements (i.e. lab space, research equipment/funding, professional development,
staffing, etc.)?
What are the greatest career challenges and satisfactions as a faculty member at your institution?

